Estudios de la Paz y el Conflicto

Revista Latinoamericana

IUDPAS-UNAH

Volumen 1, Número 2, pp. 39-54

ISSN-e: 2707-8922 | ISSN: 2707-8914

DOI: $10.5377 /$ rlpc.v1i2.9831

Julio-diciembre 2020

\title{
EDUCAÇÃO E JUSTIÇA RESTAURATIVA: OS CÍRCULOS DE CONSTRUÇÃO E CULTURA DE PAZ EM TURMAS DE ACELERAÇÃO DE ESTUDOS
}

\author{
EDUCATION AND RESTAURATIVE JUSTICE: THE CIRCLES OF CONSTRUCTION \\ AND PEACE CULTURE IN STUDY ACCELERATION CLASSES
}

\author{
Sandro de Castro Pitano \\ Universidade de Caxias do Sul (UCS) \\ scpitano@ucs.br \\ Adilson Martins Corrêa \\ Universidade de Caxias do Sul (UCS) \\ amcorrea@caxias.rs.gov.br
}

Recibido: 23-04-2020

Aceptado: 16-05-2020

Cómo citar / citation

De Castro Pitano, S., y Martins Corrêa, A. (2020). "Educação e justiça restaurativa: os círculos de construção e cultura de paz em turmas de aceleração de estudos", Estudios de la Paz y el Conflicto, Revista Latinoamericana, Volumen 1, Número 2, 39-54. DOI: 10.5377/rlpc.v1i2.9831

\begin{abstract}
Resumo
Este trabalho apresenta a experiência dos Círculos de Construção de Paz realizados junto a escolas no município de Caxias do Sul-RS, Brasil, durante o período letivo de 2019. Foram realizados 45 círculos com 11 turmas, envolvendo a participação de 177 estudantes. Após a realização dos círculos foi solicitado um feedback das turmas a respeito de suas participações nos mesmos, sendo atendido por alunos de 05 escolas, somando 50 devoluções. Foram selecionadas e analisadas 20 respostas e os participantes identificados por meio de siglas, adotando a letra $\mathrm{P}$ e o número respectivo. As respostas foram reunidas e distribuídas em 04 blocos cada, cuja análise criteriosa possibilitou que as considerações finais sintetizassem o significado dos Círculos de Construção de Paz para os estudantes, conforme o seu entendimento.
\end{abstract}




\title{
Palavras-chave
}

Escola; Círculos de Construção de Paz; Cultura de Paz; Justiça Restaurativa.

\begin{abstract}
This paper presents the experience of Peacebuilding Circles carried out with schools in the city of Caxias do Sul-RS, Brazil, during the 2019 academic period. 45 circles were held with 11 classes, involving the participation of 177 students. After the realization of the circles, feedback was requested from the classes regarding their participation in them, being attended by students from 05 schools, totaling 50 returns. Twenty responses were selected and analyzed and participants identified by means of acronyms, adopting the letter $P$ and the respective number. The answers were gathered and distributed in 04 blocks each, whose careful analysis allowed the final considerations to summarize the meaning of the Peacebuilding Circles for the students, according to their understanding.
\end{abstract}

\section{Keywords}

School; Peacebuilding Circles; Culture of Peace; Restorative Justice.

\section{INTRODUÇÃO}

A Secretaria Municipal de Educação de Caxias do Sul ${ }^{1}$, através do Grupo de Trabalho Interligar/Reconexão, vem desenvolvendo um conjunto de ações de enfrentamento à violência nas escolas da rede municipal de ensino. Trata-se das Práticas Restaurativas/Círculos de Construção de Paz, um conjunto de iniciativas que reforçam o combate e a prevenção da violência junto aos estudantes e a comunidade escolar. As principais ações, as quais serão apresentadas neste artigo, compreendem a realização de encontros circulares de abordagem restaurativa com as Turmas de Aceleração de Estudos (TAE).

As Turmas de Aceleração de Estudos são turmas compostas por alunos de estabelecimentos de ensino da rede municipal que apresentam distorção entre a idade e o ano escolar no qual se encontram. No geral, o histórico desses alunos apresenta vários eventos de reprovações, o que leva os mesmos a não acompanharem o fluxo regular conforme a estrutura legal vigente para o Ensino Fundamental ${ }^{2}$, configurando uma ampla defasagem idade/ano.

O presente artigo pretende apresentar e analisar essas ações de prevenção e combate ao conflito no ambiente escolar, considerando a participação dos estudantes nos círculos de construção de paz e a possibilidade de mudanças que elas representam. Busca-se compreendê-las a partir da construção de um novo paradigma de convivência e normatização social, ancorado no protagonismo e na autonomia ao longo dos processos.

O tema vai ao encontro da proposta de prevenção à indisciplina e à violência escolar, com aplicação da metodologia circular nas turmas de modo sistemático e com mais frequência. Vislumbra-se a obtenção de um resultado positivo nas TAE, mas igualmente importante é que as mesmas sejam práticas constantes nas turmas regulares, nas escolas que adotarem esse

\footnotetext{
${ }^{1} \mathrm{O}$ município de Caxias do Sul se localiza no nordeste do estado do Rio Grande do Sul, sul do Brasil e corresponde à segunda cidade mais populosa do estado, com cerca de 510.000 habitantes.

${ }^{2}$ Ensino Fundamental corresponde, no Brasil, à Educação Infantil e do $1^{\circ}$ ao $9^{\circ}$ anos, sendo dividida do $1^{\circ}$ ao $5^{\circ}$ (anos iniciais) e do $6^{\circ}$ ao $9^{\circ}$ (anos finais).

Estudios de la Paz y el Conflicto, Revista Latinoamericana, IUDPAS-UNAH, Volumen 1, Número 2, julio-diciembre 2020, pp. 39-54. DOI: $10.5377 /$ rlpc.v1i2.9831.
} 
método de resolução de conflitos. Almeja-se que essas escolas construam uma cultura de paz sistemática e permanente em todos os seus níveis de ensino, assumindo o protagonismo no enfrentamento da violência cotidiana.

\section{AS INICIATIVAS POR UMA CULTURA DA PAZ}

Assim como a sociedade em geral, a escola como instituição social também almeja a paz, juntamente como outros valores: liberdade, autonomia, respeito, justiça, etc. Nessa perspectiva, "entende-se que a paz está fundada na justiça", o que demonstra a relevância "de construir relacionamentos e estruturas sociais justas, incluindo respeito aos direitos humanos, cultura pela paz, comunicação não violenta e o direito e respeito à vida" (Lederach, 2012: 16). E os relacionamentos correspondentes à cultura da paz devem ser pensados como movimento permanente:

"Em vez de ver a paz como uma condição final, estática, a transformação de conflitos a considera uma qualidade relacional em continua evolução e desenvolvimento. O trabalho de paz, portanto, se caracteriza por esforços intencionais para tratar as marés do conflito humano através das abordagens não violentas, que cuidam das questões pendentes e aumentam a compreensão, igualdade e respeito nos relacionamentos" (Lederach, 2012: 34).

Segundo Mullet e Amstutz (2005), a paz começa com o se sentir incluído e com a inclusão dos demais componentes da comunidade. Convivência significa respeitar os outros, seu ponto de vista, considerando a igualdade e a pluralidade de ideias, princípios basilares para os círculos de paz.

Os círculos de construção de paz fazem parte de um eixo de trabalho da Comissão Interna de Prevenção a Acidentes e Violência Escolar (CIPAVE). A CIPAVE foi implantada pela Prefeitura Municipal de Caxias do Sul por meio de uma parceria entre a Secretaria Municipal de Segurança Pública e Proteção Social e a Secretaria Municipal da Educação, com o objetivo de diagnosticar as vulnerabilidades no âmbito escolar e planejar ações preventivas visando à resolução dos problemas de forma eficaz.

A iniciativa criada pela Lei $\mathrm{n}^{\circ} 6.025$, de 12 de junho de 2003 e regulamentada pelo Decreto $\mathrm{n}^{\mathrm{o}}$ 13.097, de 8 de fevereiro de 2007 tornou-se, em 2012, lei estadual, baseada no programa de Caxias do Sul. No município, todas as 81 escolas de Ensino Fundamental têm sua comissão interna composta por pais, alunos, funcionários, direção e professores, com número proporcional aos estudantes matriculados. Essa comissão se reúne no início de cada ano letivo, realiza um diagnóstico e elabora um plano de ação a ser executado durante o calendário escolar.

As atividades desenvolvidas nas escolas envolvem os seguintes eixos de trabalho (CIPAVE, 2015):

- Conservação do patrimônio público, contemplando palestras com a comunidade escolar, diagnóstico de violência na comunidade com intervenções educativas, círculos de paz, oficinas e capacitação de servidores sobre preservação e proteção do patrimônio através de agentes públicos da infraestrutura, guarda municipal e consequências legais sobre a depredação do mesmo sob os pontos de vista social, cultural e penal.

- Prevenção ao uso de drogas na escola, promovendo palestras com órgãos de segurança e saúde com abordagens preventivas e educativas, vídeos e concursos sobre 
o tema, contando com a participação da guarda municipal, de órgãos policiais e da secretaria de saúde e ação social.

- Prevenção de incêndios, evacuação e abandono do local do sinistro, uso dos equipamentos de combate a incêndio, primeiros socorros, com ações de prevenção por meio de palestras, visitas e abordagens preventivas de acidentes em conjunto com o corpo de bombeiros e a secretaria de saúde.

- Prevenção a acidentes de trânsito através da escola pública de trânsito, contando com palestras, concursos de vídeos e redação, semana municipal de prevenção a acidentes de trânsito e outras iniciativas desenvolvidas em conjunto com a secretaria municipal de trânsito, polícia rodoviária federal e secretaria da saúde.

- Segurança pública violência escolar, promovendo palestras e abordagens sobre causas e consequências da violência no ambiente escolar em conjunto com o conselho tutelar e demais órgãos de segurança municipal, estadual e federal.

- Pacificação restaurativa através de ações preventivas, implementadas por meio de encontros e contando com as ferramentas pacificadoras de Justiça Restaurativa e Círculos de Construção de Paz.

Essas experiências gestaram o Programa Municipal de Pacificação Restaurativa - Caxias da Paz, instituído pela lei municipal no 7.754, de 2014. O Programa é resultado de uma construção progressiva entre o Município de Caxias do Sul, o poder judiciário (por meio do Centro Judiciário de Solução de Conflitos e Cidadania - CEJUSC), fundação Universidade de Caxias do Sul (UCS) e Fundação Caxias. Propõe a compreensão da justiça como poder da comunidade, partindo da ideia de que a justiça não se esgota na esfera judicial, sendo uma função que se exerce no cotidiano da convivência social. Os diversos conflitos, tais como ocorrências de bullying, ameaças e agressões de menor potencial ofensivo, antes eram encaminhados pela Secretaria Municipal de Educação para a Central de Pacificação Restaurativa da Infância e Juventude (CPR/IJ).

Até o ano de 2017, o programa de Justiça Restaurativa/Círculos de Construção de Paz funcionava junto à Central de Pacificação Restaurativa da Infância e Juventude, nas dependências da Secretaria de Segurança Pública e Proteção Social, a qual atendia toda a rede de ensino de Caxias do Sul, o que compreendia as escolas municipais, estaduais e particulares com caráter preventivo e restaurativo, conforme designação do caso.

A partir de então foi remodelado o programa e os facilitadores realocados para a Secretaria Municipal da Educação, quando foi elaborado o Grupo de Trabalho Interligar II - Reconexão. Posteriormente, apenas GT Interligar, iniciando uma nova configuração e planejamento de trabalho com círculos de construção de paz, focados nas escolas municipais de Caxias do Sul-RS.

Ante a implementação das diretrizes do programa na Secretaria Municipal da Educação, com um viés preventivo, foi proporcionada a formação de um grupo composto por quinze profissionais da educação, incluindo professores, assistentes sociais e psicólogas. Realizaram o curso de facilitadores de círculos de construção de paz para tornarem-se aptos a atuar na assessoria pedagógica da rede municipal de círculos de construção de paz, inicialmente como co-facilitadores e, posteriormente, como facilitadores de círculos.

No ano de 2017 iniciou-se a aplicação da metodologia de diálogo através dos círculos de construção de paz e a realização de ações e fortalecimentos de vínculos. Também teve início

Estudios de la Paz y el Conflicto, Revista Latinoamericana, IUDPAS-UNAH, Volumen 1, Número 2, julio-diciembre 2020, pp. 39-54. DOI: $10.5377 /$ rlpc.v1i2.9831. 
a formação experimental de profissionais da educação de duas escolas-piloto da rede municipal de ensino, funcionando como um laboratório.

\section{Cultura da paz}

A contemporaneidade impõe um modo de vida pautado pela rapidez com que se processa, dificultando o diálogo e a atenção interpessoal. É pouco percebido a existência de um egoísmo exacerbado (egocentrismo), situação que leva cada pessoa a olhar somente para si próprio, alimentando o individualismo assentado no ter, na materialidade. Esse ritmo de vida atual atinge a maioria das pessoas, independente de idade ou classe social. Somos sujeitos de um mundo moderno e tecnológico, com fluidez alucinante, mas vazio no sentido humano das relações e valores.

A construção da paz é um elemento de prática diária através de nossas atitudes e envolve diretamente a forma como vemos o outro e como nos relacionamos com ele. A paz não se constrói por si própria, mas se sustenta alicerçada em valores sociais e culturais, humanos, portanto. Uma cultura de paz consiste em criar estratégias pedagógicas de boa convivência, de respeito mútuo, de reflexão, compaixão, auto avaliação, em que cada educando, no contexto escolar, assume o seu papel naquele espaço de convivência (CIPAVE, 2015).

No contexto escolar, uma cultura de Paz visa subsidiar professores e gestores na busca de soluções para conflitos e situações de violência, tanto física como simbólica. Opera por meio de abordagens restaurativas, mediação, círculos de construção de paz e comunicação não violenta, abordando a importância da convivência social no ambiente escolar.

Os círculos de construção de paz oferecem uma ferramenta que vêm a servir como um instrumento a ser utilizado na abordagem de prevenção de conflitos de qualquer natureza. Instrumento este que resgata de modo simples e eficaz a oportunidade de as pessoas se reunirem, contarem suas histórias, dividirem suas angústias a criarem empatia a partir da fala e da escuta de cada participante. Na definição de Watson e Pranis (2015), os círculos são relevantes para todos os grupos etários. Representam um momento de manifestação de cada participante que se reconecta com ele próprio e com os outros, tendo como objetivo criar um espaço seguro a fim de que todas as vozes sejam ouvidas e que cada participante seja encorajado a caminhar em direção ao seu melhor como ser humano.

Segundo Menda (2014), a escola é parte do contexto social e a relação entre os pares é a que mais gera conflitos. De modo geral, a escola reproduz a sociedade e os conflitos concretamente existentes na realidade das comunidades tendem a ser reproduzidos pelos estudantes. Uma das funções sociais da escola é justamente quebrar este paradigma e fomentar o conhecimento social, sua elaboração e discussão, proporcionar a apropriação do respeito às regras e normas de convivência e a educação para paz. É importante destacar que a escola, normalmente, dá muita ênfase aos aspectos cognitivos e pouco aos aspectos sociais e emocionais.

A metodologia circular é inspirada nas práticas de convivência das tribos indígenas da América do Norte, no Canadá, efetivadas judicialmente pelo juiz canadense Barry Stuart, que elaborou e iniciou as praticas através dos círculos de sentença, estendendo-se, na sequência, aos Estados Unidos da América. Também praticados por tribos da Nova Zelândia e da Austrália, esses encontros consistem em reunir as pessoas em círculos para que, através da escuta respeitosa e empática, possam se perceber e se reconectar a um grupo, dividir suas 
vivências, sejam elas positivas ou negativas, dando-lhes um forte senso de pertencimento (Justiça Restaurativa do Brasil, 2015: 16).

Essa prática transpõe o tempo e é utilizada por quase todas as culturas. Os registros de primeiros círculos humanos remetem ao redor de uma fogueira, onde se estabelecia uma melhor distribuição do calor com a mesma intensidade para cada componente do círculo. Os círculos constituem um símbolo potente de pertencimento, pois seu formato de reunião tende a criar uma interligação comunitária, a partir de princípios como conexão, inclusão, igualdade, equidade, pertencimento, justiça e empatia. Além disso, na dinâmica de um círculo não há primeiro nem último, pois sua natureza circular estabelece uma igualdade de condição entre todos os participantes, sem uma sobreposição hierárquica (Costello e Wachtel, 2011: 7).

No contexto brasileiro, o círculo foi apropriado pelo educador Paulo Freire com a denominação Círculo de Cultura, no começo dos anos de 1960. Criado no âmbito de práticas de alfabetização, o seu intuito era igualar a todos, superando a hierarquia do ensino bancário em que o professor, detentor de todo o conhecimento, deposita conteúdo no estudante, o mero receptor de informações (Freire, 2002).

Neste sentido segundo Pelizzoli (2015), os círculos de cultura de paz trazem de cada indivíduo suas vivências e experiências, o seu saber, vindo a se constituir sujeito ativo da própria aprendizagem. As relações humanas, horizontalizadas, deixam claro a relevância da participação coletiva. Há um moderador que interage com todos no intuito de alcançar o conhecimento coletivo. Por meio do diálogo que aguça a reflexão e a ação os participantes aproximam-se e promovem relações de afetividade, humildade, respeito, amor, uns pelos outros e pelo mundo.

As ideias sobre práticas de justiça restaurativa começaram a dar os primeiros passos em meados da década de 1970, nos Estados Unidos, com a criação do Instituto de Mediação e Resolução de Conflitos e em 1976, no Canadá com o Centro Comunitário de Justiça Restaurativa Vitória. Na mesma década alguns países europeus aderiram timidamente à metodologia, que avançou na década seguinte (anos 1980) em países da Oceania, como Nova Zelândia e Austrália. Tais países consolidaram a metodologia ao desenvolverem centros de mediação de conflitos (Araújo e Lorenzini, 2015: 24).

Assim, muito além da disposição de um modelo geométrico, os círculos são uma forma de estabelecer conexão, interligar pessoas, explorar e viver a experiência do outro em vez de excluí-lo. Falar, ouvir e ser ouvido, perceber a importância de um consenso grupal, o que dá a cada participante uma mesma importância, com sua história e responsabilidade naquele espaço de acolhimento e equidade.

No Brasil, a prática de Justiça Restaurativa (JR) se baseia na Resolução ${ }^{\circ} 225$ do Conselho Nacional de Justiça (2016); constitui-se como um conjunto ordenado e sistêmico de princípios, métodos, técnicas e atividades próprias, que visa à conscientização sobre fatores relacionais, institucionais e sociais motivadores de conflitos e violência, conforme parâmetros normativos de aplicação como projeto de Justiça Restaurativa nas diversas instâncias sociais. Segundo estabelece a Resolução:

"As práticas restaurativas terão como foco a satisfação das necessidades de todos os envolvidos, a responsabilização ativa daqueles que contribuíram direta ou indiretamente para a ocorrência do fato danoso e o empoderamento da comunidade, destacando a necessidade da reparação do dano e da recomposição do tecido social rompido pelo conflito e suas implicações para o futuro" (Art. $1^{\text {o }}$, III, Resolução n²25 do CNJ).

Estudios de la Paz y el Conflicto, Revista Latinoamericana, IUDPAS-UNAH, Volumen 1, Número 2, julio-diciembre 2020, pp. 39-54. DOI: 10.5377/rlpc.v1i2.9831. 
A Resolução trata das situações de conflitos em que há dano pessoal ou material, tendo sido acionado o sistema judiciário, sendo que vítima e ofensor tem a possibilidade de realizar práticas auto compositivas por meios consensuais na reparação do dano. Também há possibilidade de recomposição das relações em situações futuras, constituindo um novo tecido social.

Também a Base Nacional Comum Curricular (BNCC), da Educação Básica, na sua competência $\mathrm{n}^{\circ}$ 09, trata sobre Empatia e Cooperação, destacando o exercício da empatia e do diálogo para a resolução de conflitos. A cooperação visa a promover o respeito ao outro e aos direitos humanos, estimulando o acolhimento e a valorização da diversidade, sem preconceito de qualquer natureza, o que vem ao encontro das práticas de diálogos nas escolas através dos círculos de construção de paz.

\section{OS CÍRCULOS DE CONSTRUÇÃO DE PAZ}

Definir y delimitar la extrema derecha resulta O Círculo de Construção de Paz (CCP) é uma metodologia dialética, que pode ser aplicada como ferramenta restaurativa, conduzida por facilitadores. É um espaço proporcionado aos participantes que buscam, por meio do diálogo, se conhecer, criar empatia, fortalecer ou restaurar vínculos e falar sobre algum tipo de conflito existente (Pranis, 2010: 09).

Um Círculo de Construção de Paz é baseado em etapas e se constitui por meio de sensibilização, construção de valores, diretrizes e perguntas norteadoras, oportunizando a todos os participantes que relatem suas histórias de modo respeitoso, contando com a escuta qualificada. Os círculos de construção de paz:

[...] "reúnem pessoas que se tratam como iguais e mantém trocas honestas sobre questões difíceis

e experiências dolorosas, num ambiente de respeito e atenção amorosa para com todos. Esses círculos estão sendo realizadas em contextos cada vez mais variados, oferecendo espaços onde pessoas com visões muito diferentes podem se reunir para falar francamente sobre conflito, dor e raiva e sair se sentindo bem em relação a si mesmas e aos outros" (Pranis, 2010: 18).

O ritual do círculo ajuda a unir pessoas, tornando-se um instrumento eficiente para a promoção da cultura da paz na sua essência. Seus resultados são surpreendentes nas escolas, onde cria um clima positivo de compaixão e empatia nas relações cotidianas e no aprendizado, fortalecendo a convivência, qualificando relações e promovendo reflexão com troca de experiências entre os participantes (Pranis, 2010: 11).

É fundamental que a realização de um Círculo de Construção de Paz/Encontro Restaurativo transcorra conforme o roteiro previamente estabelecido. É ele que vai dar segurança aos passos do processo circular a serem seguidos para que a experiência se efetive de acordo com todos os seus preceitos, com a cerimônia de abertura e fechamento; o poder da palavra, que empodera e serve como equalizador da escuta dos participantes (todos podem fazer uso dele ou não, ou seja, todos têm o poder de decidir). Os facilitadores que conduzem as rodadas de perguntas, não devem emitir aconselhamentos ou julgamentos durante o círculo; é um momento da construção coletiva de valores, em que cada participante traz o melhor de si como valor do momento ou da vida.

$\mathrm{O}$ encontro circular garante aos estudantes que todos sejam respeitados, que tenham a oportunidade de falar sobre seus desejos, sentimentos e anseios, cada um com sua história de 
vida, sem ser interrompido ou julgado. Todos são iguais em um principio de equidade; naquele momento, ninguém é mais importante do que o outro, todos as manifestações são acolhidas pelo grupo, igualmente (Pranis, 2010: 20; Pelizzoli, 2015: 210; Justiça Restaurativa do Brasil, 2015, p.16).

Segundo Pranis (2010), os círculos de construção de paz podem ser direcionados com a finalidade de atender alguma situação específica do grupo ao qual foi planejado. Sua criação emerge da necessidade de enfrentamento às demandas e problemas que foram surgindo naquele contexto vivencial determinado. Por isso as terminologias foram se adequando, sendo ainda um processo de estudo e de construção permanente; são, em síntese, círculos de diálogo, de compreensão, reestabelecimento de vínculos, sentenciamento, apoio, construção de senso comunitário, resolução de conflitos, reintegração, celebração, acolhimento, pertencimento, de luto, etc.

Como explicam Araújo e Lorenzoni (2015), a implementação de programas restaurativos no ambiente escolar permite prevenir situações de conflito, pois a escuta, o empoderamento através da fala e a empatia são capazes de construir espaços de reconhecimento e pertencimento muitas vezes sufocados, os quais vem à tona no momento de participação no círculo, que serve como aprimoramento e ressignificação para alunos e professores de práticas educacionais com foco na capacidade de dialogar e resolver situações de convivência ou conflituosas. É uma ferramenta de esperança, auxiliando na compreensão de si e do outro.

A escola é um espaço indissociável dos demais que compõem a realidade social, passando pela cultura e relações discursivas do politicamente correto, ou seja, tudo que produzido no ambiente escolar é concebido enquanto uma verdade. Também é o local de desenvolvimento das potencialidades relacionais, onde se estabelecem o respeito e a singularidade das diferenças de cada um na sua essência. Em muitas situações a escola é o único espaço onde é oportunizado às crianças e adolescentes essa vivência, mas é preciso que esse espaço seja de construção, no qual os alunos sejam protagonistas e atores capazes de mudar a relação de conflito (Araújo e Lorenzoni, 2015: 71).

Nesta perspectiva, a violência na escola não é um fenômeno novo. O que está deixando a sociedade aflita e preocupada é a incidência e gravidade dos eventos violentos que estão acontecendo naquele espaço. A violência assusta em qualquer situação, rompe relações, deixa traumas, mas quando acontece em um ambiente que deveria ser de proteção, de aprendizado e de relações positivas, ela impacta ainda mais. Afinal, a escola é o primeiro lugar de convivência com as diferenças depois da família, por isso, é o momento de pensarmos nos fatores que geram o rompimento destas relações e buscar ações de prevenção através de uma cultura de paz.

\section{METODOLOGIA E RESULTADOS}

A Rede Municipal de Ensino de Caxias do Sul-RS conta com 81 escolas de Ensino Fundamental, somando aproximadamente 40 mil alunos e 3 mil professores, distribuídos entre Ensino Fundamental, Educação Especial e Educação de Jovens e Adultos (EJA).

O Ensino Fundamental compreende os alunos da Educação Infantil ao $9^{\circ}$ Ano; a Educação de Jovens e Adultos (EJA) que reúne alunos em estudos noturnos, acima de 18 anos. A Educação Especial atende os alunos com deficiência, devidamente documentada por atestado médico comprovando o Código Internacional de Doenças (CID). Para qualificar as questões

Estudios de la Paz y el Conflicto, Revista Latinoamericana, IUDPAS-UNAH, Volumen 1, Número 2, julio-diciembre 2020, pp. 39-54. DOI: $10.5377 /$ rlpc.v1i2.9831. 
relativas à aprendizagem, todas as escolas municipais têm o apoio de um coordenador pedagógico, responsável por oferecer suporte didático e técnico aos professores.

Dentro das abordagens de Círculos de Construção de Paz, há necessidade de um trabalho mais sistemático nas relações com as turmas de aceleração de estudos devido à sua tipicidade de diferença e distorção idade/série. Normalmente elas envolvem muitas questões disciplinares, dificuldades de convivência, relação conflituosa de gênero e algum tipo de deficiência, mesmo sem confirmação médica.

Para implantar uma Turma de Aceleração de Estudos (TAE) a escola deve seguir os seguintes critérios definidos pela secretaria de educação:

- Identificar os estudantes com defasagem de dois anos ou mais de escolarização.

- Utilizar os Planos de Estudo e da Matriz Curriculares disponibilizados pela mantenedora, os quais servirão de base para a construção dos Planos de Trabalho pelos professores.

- Definir o professor-referência (professor convidado pela direção da escola por sua identificação com as práticas pedagógicas de caráter social), conforme orientação da mantenedora.

- Formalizar a adesão de cada estudante à Turma de Aceleração de Estudos, através da assinatura de termo de compromisso por parte dos responsáveis e, posteriormente, anexar à pasta do estudante em função da modalidade de ensino (SMED).

Esses critérios que norteiam a formação de Turmas de Aceleração de Estudos são prédefinidos conjuntamente com as escolas e mantenedora (Secretaria Municipal de Educação), definindo quando há necessidade de implementação da modalidade naquele núcleo escolar.

A Secretaria Municipal da Educação, em consonância com o regimento das escolas, definiu as Turmas de Aceleração de Estudos na rede devido à impossibilidade de os adolescentes frequentarem o ensino noturno a partir de 2019, conforme lei federal que regimenta a Educação de Jovens e Adultos (EJA).

Dentro dos critérios de implementação definidos pela mantenedora, foi solicitada a formação de 11 turmas de Turmas de Aceleração de Estudos, no ano de 2019, por adesão das direções das seguintes unidades escolares:

- Escola Municipal de Ensino Fundamental Machado de Assis

- Escola Municipal de Ensino Fundamental Presidente Tancredo de Almeida Neves

- Escola Municipal de Ensino Fundamental Professora Ilda Clara Sebben Barazetti

- Escola Municipal de Ensino Fundamental Paulo Freire

- Escola Municipal de Ensino Fundamental Renato João Cesa

- Escola Municipal de Ensino Fundamental Guerino Zugno

- Escola Municipal de Ensino Fundamental Dezenove de Abril

- Escola Municipal de Ensino Fundamental Dolaimes Stédile Angeli - CAIC

- Escola Municipal de Ensino Fundamental Fioravante Webber

- Escola Municipal de Ensino Fundamental Governador Leonel de Moura Brizola

- Escola Municipal de Ensino Fundamental Ruben Bento Alves

Cada escola foi contemplada com, no mínimo, uma Turma de Aceleração de Estudos (TAE), conforme os critérios regimentais e a demanda da comunidade, devendo possuir um espaço adequado.

Estudios de la Paz y el Conflicto, Revista Latinoamericana, IUDPAS-UNAH, Volumen 1, Número 2, julio-diciembre 2020, pp. 39-54. DOI: 10.5377/rlpc.v1i2.9831 
A partir da formação das turmas foram oferecidos através do programa Cipave/REconexão, abordagens restaurativas através dos Círculos de Construção de Paz às escolas participantes, como uma ação preventiva à eventuais situações de conflitos em função de necessidades e peculiaridades dos alunos envolvidos. No ano anterior (2018), foi detectado um número muito elevado de evasão escolar, vários eventos de indisciplina $\mathrm{e}$ conflitos entre os alunos, professores e gestores o que nos direcionou a pensar conjuntamente em ações preventivas de cultura de paz.

Um convite por adesão para participar de Círculos de Construção de Paz (CCP) foi oferecido para todas as escolas com turmas de Turma de Aceleração de Estudos (TAE), através de ofício circular, encaminhado pelo grupo Cipave/REconexão. Todas as 11 escolas que atendem às Turmas de Aceleração de Estudos (TAE) aderiram, o que corresponde a 100\% das escolas com a modalidade na Rede Municipal de Ensino no ano de 2019.

Em um primeiro movimento, as escolas foram convidadas para participar de um encontro denominado pré-circulo, em conjunto com os assessores/facilitadores de Círculos de Construção de Paz (CCP), da Secretaria Municipal da Educação.

Nesse encontro ocorreu uma conversa com a direção e a coordenação pedagógica, quando são elencadas algumas características da realidade social da escola, das turmas, situações corriqueiras de relações, dificuldades de relacionamento, aprendizagem, frequência, número de alunos, horários e dias disponíveis para a realização do círculo. O pré-círculo visa obter convergências com cada um sobre os fatos ocorridos com a turma, suas consequências, o restante do procedimento restaurativo, os outros participantes que serão convidados e a vontade de prosseguirem nas etapas seguintes. Isto é feito buscando o estabelecimento de um vínculo de confiança entre proponentes, participantes e facilitadores.

Após a realização dos pré-círculos individuais com representante de cada escola, foram definidos os primeiros Círculos de Construção de Paz (CCP), na proporção de quatro círculos por escola no decorrer do ano letivo de 2019, totalizando 44 círculos. Em uma única escola foi programada a realização de cinco círculos em função de sua necessidade específica.

Os mesmos iniciaram no mês de março de 2019, finalizando em dezembro do mesmo ano. Todos os círculos tiveram sua proposta fundamentada no diálogo e no esforço pelo fortalecimento de vínculos. Portanto, 10 escolas foram contempladas com quatro e uma escola com cinco Círculos de Construção de Paz (CCP), totalizando 45 círculos, com 177 alunos participantes, perfazendo 574 participações.

Considera-se participante cada um dos alunos que estiveram presentes, no mínimo, um círculo. Já as Participações resultam da soma do número de vezes que cada participante esteve presente em um círculo. Ou seja, um mesmo aluno representa quatro participações na turma.

Após a realização do último Círculo de Construção de Paz (CCP), foi solicitado um feedback das turmas, a respeito de suas participações nos círculos com as seguintes questões: "O que você achou desta experiência circular? A leva como lição de vida? Deixe seus comentários, voluntariamente."

Obteve-se retorno e respostas das seguintes escolas: Escola Municipal de Ensino Fundamental Machado de Assis, Escola Municipal de Ensino Fundamental Paulo Freire, Escola Municipal de Ensino Fundamental Guerino Zugno, Escola Municipal de Ensino Fundamental Dezenove de Abril e Escola Municipal de Ensino Fundamental Fioravante Webber. Dentre essas cinco escolas, somaram-se um total de 50 devoluções, representando uma taxa de $28,2 \%$ de retornos por parte dos participantes. Deste número total foram

Estudios de la Paz y el Conflicto, Revista Latinoamericana, IUDPAS-UNAH, Volumen 1, Número 2, julio-diciembre 2020, pp. 39-54. DOI: $10.5377 /$ rlpc.v1i2.9831. 
selecionadas para análise 20 respostas, o que corresponde a $40 \%$ dos alunos que responderam aos feedbacks.

Em se tratando de respeito à participação de alunos e das escolas envolvidas, os mesmos serão referenciados por siglas sequenciais, do 'Participante 01' ao 'Participante 20' (P.1 a P.20), sem a citação dos nomes e das escolas em função do sigilo da pesquisa. Os 20 participantes e as respectivas respostas aqui apresentados serão divididos em quatro temas, reunidos por afinidade e discutidos a partir do sentimento a respeito por eles relatados.

Em um primeiro momento faremos uma análise a respeito dos círculos, divididos em quatro blocos com respostas transcritas na íntegra. O primeiro bloco trata das questões de reflexão, expressão, diálogo e pertencimento, mais voltado à interação e à participação na atividade. O segundo bloco trata da felicidade, da paz e do repensar os conflitos, com temas voltados à espiritualidade e os sentimentos. O terceiro bloco trata dos valores, do respeito da igualdade e da equidade, sobre falas de valores na educação e na vida e o quarto bloco é sobre relação, desabafo e fortalecimento de vínculos, que traduz o pertencimento e a empatia com relação ao outro.

\section{Bloco 1 - a participação (P.1 a P.5)}

P. 01- "Eu achei bem interessante, pois, foi um modo de nos conhecermos mais e refletirmos sobre nosso presente e nosso futuro, assim como desabafar um pouco no círculo. Tudo isto faz falta no dia a dia e o círculo supriu muito bem".

P. 02- "Foi bom vou levar esta experiência para minha vida, aprendi bastante sobre diversos assuntos, conversamos sobre raça, orientação sexual, conversamos sobre um grupo de pessoas dos Estados Unidos que era comandado por pessoas brancas que odiavam pessoas com um tom de pele diferente deles".

P. 03- "Eu achei bastante interessante essa aula, porque é para nós refletir nisso. É foi uma forma de nós se abrir com elas e com a turma, é foi muito legal a gente tá na roda e olhar na cara de todo mundo, eu espero que elas vem de novo, porque eu gostei muito".

P. 04- "Eu me senti mais aliviado em me expressar".

P. 05- "Eu me senti feliz é muito legal, o caminho entra na mente e relaxa é bom para se comunicar mais com os colegas. Muito bom ótimo, ainda bem que elas vão vir de novo".

O círculo vem se apresentando de suma importância como metodologia de práticas restaurativas e diálogo, com aplicabilidade em diversas áreas, por promover o encontro igualitário entre sujeitos. O ritual do círculo ajuda unir as pessoas tornando-se um instrumento eficiente para a cultura da paz, criando um clima positivo nas relações interpessoais. Os círculos propiciam um meio de estabelecer conexão entre as pessoas, possibilitando estarem frente a frente na convivência e na partilha das ideias e valores nas abordagens restaurativas. $\mathrm{O}$ foco principal emerge da força do círculo, da oportunidade para que as pessoas se escutem, oferecendo a todos a mesma oportunidade, sem exceção. Gerando um sentimento de inclusão e pertencimento, garantindo no espaço a igualdade, a responsabilidade e a conexão (Pranis, 2010; Grecco, et. al, 2014).

Percebe-se que os círculos proporcionam aos participantes um bem-estar em relação ao poder de fala horizontalizado. No quotidiano da escola muitos alunos não têm essa oportunidade, ou são impedidos de expressar-se, o que limita a participação e a integração com os colegas ou com o grupo. Em casos mais específicos, em função da falta de hábito, 
advinda de um contexto social e de uma educação familiar que não se fazem presentes no núcleo familiar.

Sendo assim, o círculo se revela como um símbolo potente, sua forma implica comunidade, conexão, inclusão, justiça, igualdade e integridade, permitindo que o aluno se sinta acolhido e ouvido. Perceber que todos têm as mesmas possibilidades faz com que ele se sinta pertencente aquele grupo, onde não há maior ou menor, primeiro ou último, por sua própria natureza circular.

\section{Bloco 2 - o significado de paz (P.6 a P.10)}

P. 06- "Achei importante para nos conhecermos melhor e também nos falarmos coisas que talvez não falaria e enfim foi uma experiência legal".

P. 07- "Eu amei essa roda, falei o que me deixou leve e feliz e gostei de me expressar ter um minuto para ouvir e ser ouvida, precisava disso e queria mais vezes".

P. 08- "Eu me senti confiante feliz, senti paz, me senti relaxada".

P. 09- "Me senti um minuto de paz e tranquilidade, gostei muito mesmo".

P. 10- "Eu achei que foi bom, eu levei coisas boas, e levei que brigar não vale a pena, por isso vire as costas quando tiverem tirando".

Neste bloco de respostas estão destacadas as opiniões voltadas à reflexão diante dos conflitos e o papel dos círculos. Em todos os encontros e modelos de círculos abrem-se oportunidades para que os participantes explorem fatos, histórias, sentimentos e resoluções. Cada um é instigado pelo facilitador, através das perguntas empáticas, a expressar seus sentimentos.

Os círculos por sua natureza e estrutura, transmitem certas ideias importantes sem a necessidade de discussão, de conselho ou juízo de valores. Estabelecendo uma teia de conexões a partir do princípio de que o círculo é deles e que a responsabilidade é construída na participação individual e coletiva, olhando no olho, usando seu próprio tempo, com empoderamento de fala e confiança no grupo.

\section{Bloco 3 - os valores (P.10 a P.15)}

P. 01- "Eu achei muito legal a apresentação de hoje e bom para nos refletir e pensar no que estamos falando e fazendo e para pensar o que vamos querer das nossas vidas".

P. 12- "Eu achei muito bom para refletirmos sobre algo que talvez não sabemos e gostei sobre os valores das retas e também as atividades sobre os números e perguntas"

P. 13- "Eu achei muito interessante e muito legal, elas são muito legais só respeito que é bom só conversamos um monte".

P. 14- "Minha opinião é que foi bom porque fez eu refletir mais e pensar na questão do respeito e igualdade das pessoas".

P. 15- "Eu achei muito bom falar um pouco de nossa vida, bom tudo que nós fizemos".

À medida que o círculo avança, traz muito do nosso eu, da empatia e da compaixão com o outro. Percebemos que o que somos e temos é muito semelhante ao outro, principalmente nos momentos da construção de valores de vida e contação de histórias. Este relacionamento consigo é impactado por crenças e valores centrais, os quais, muitas vezes, são ignorados no quotidiano da escola.

Estudios de la Paz y el Conflicto, Revista Latinoamericana, IUDPAS-UNAH, Volumen 1, Número 2, julio-diciembre 2020, pp. 39-54. DOI: $10.5377 /$ rlpc.v1i2.9831. 
Conhecendo melhor a nós e aos outros conseguimos promover a interconectividade subjetiva, relacional. Precisamos nos reconhecer como partes que contribuem para os relacionamentos saudáveis e para isto precisamos ver o outro e nos colocarmos no lugar do outro (Evans e Vaandering, 2018: 77).

"Ao dar aos participantes uma oportunidade de cerimonial de escutarem e serem escutados, a confiança mútua acaba sendo desenvolvida. Com o tempo, esta confiança e pratica de escutar e falar se transfere para os relacionamentos fora do círculo, impactando positivamente o modo com as pessoas se relacionam" (Evans e Vaandering, 2018: 82).

Diante destes relatos, os Círculos de Construção de Paz vêm resgatar através desta pratica o desenvolvimento de habilidades e solidariedade, senso de pertencimento, colaboração e responsabilidade, espaço-tempo construído no coletivo do círculo proporcionando um resgate de relações saudáveis através do diálogo.

\section{Bloco 4 - os vínculos (P.15 a P.20)}

P. 16- "Eu achei muito legal fazer parte do círculo da paz conhecer o problema de outras pessoas e poder ajudar eu levo de lição de vida sempre ajudar o próximo, aprendi com vocês a conhecer a versão das outras pessoas e ajudar".

P. 17- "Eu achei muito legal participar do círculo da paz, pra mim foi uma experiência ótima. Eu levo uma lição de vida sempre ajudar o próximo".

P. 18- "É uma forma bem interessante de nós conhecermos as coisas melhor e sempre ajudar o próximo".

P. 19- "Eu gostei muito das perguntas que as professoras fizeram, gostei mais quando ela perguntou quem nos dava força, incentivo, motivação, quem nos ajudava etc. Gostei quando perguntaram quem era nosso herói, falei que era meus pais, falei quem me dava força era meus pais e meu namorado que esta comigo ele e meus pais".

P. 20- "Eu achei muito importante para nos refletir os nossos pensamentos, termos um pensamento diferente, melhor para nós não cometermos muito erros graves. Falar algo tão intimo que gostaria muito de falar na roda com os amigos, colegas e professor".

Neste bloco final das respostas traremos em evidencia as manifestações segundo o sentimento de participação que os alunos trouxeram. Evidenciaram a reflexão, o poder da palavra, motivação, família, o próximo, vida e o ponto de vista a respeito da vida.

Watson e Pranis (2015: 23), afirmam que:

"O círculo é uma ferramenta poderosa para função básica da comunidade na definição como estar juntos, o que inclui a construção de relacionamentos, estabelecendo as normas de trabalhos com as diferenças. $\mathrm{O}$ círculo preenche a função comunitária básica: mantém um equilíbrio saudável entre as necessidades individuais e as necessidades do grupo".

Os círculos se constituem como uma ponte de fortalecimento frente a vivência e às relações entre as crianças e os adolescentes. Desempenham uma influência maior que a própria inteligência, fortalecendo o elo de reciprocidade e conexão ao se prever o sucesso nesta transição para a vida adulta. Desenvolver hábitos de empatia, respeito, valores e atitudes emocionais não são meros traços genéticos, mas sim princípios cultivados por meio da interação com os outros (Watson e Pranis, 2015)

Esse processo circular segundo Mullet e Amstutz (2005), Watson e Pranis (2015) também oferece a oportunidade de identificar emoções que o participante pode gerenciar Estudios de la Paz y el Conflicto, Revista Latinoamericana, IUDPAS-UNAH, Volumen 1, Número 2, julio-diciembre 2020, pp. 39-54. DOI: 10.5377/rlpc.v1i2.9831 
adequadamente. Fomenta a autoconscientização através da conexão com os outros em momentos como o da contação de histórias, buscando algo em comum ao compartilhar necessidades de modo construtivo, com senso de relacionamentos coletivo e comunitário. Concentrando força para nutrir todos seus membros e afirmando a escola como campo fértil no sentido da construção de uma cultura de paz, através da confiança, da solidariedade e do compartilhamento com o outro.

"Em vez de paz como uma condição final, estática, a transformação de conflitos a considera uma qualidade relacional em continua evolução e desenvolvimento. O trabalho de paz, portanto se caracteriza para tratar do conflito humano através de abordagens não violentas, que cuidam das questões pendentes e aumentam a compreensão, igualdade e respeito nos relacionamentos" (Lederach, 2012: 34).

A participação nos Círculos de Construção de Paz traz aos jovens valores muito fortes e afirmativos. Na proporção progressiva de círculos com o mesmo grupo, com a mesma turma, desperta a confiança dos participantes ao longo dos encontros, abrindo um campo fértil para a cultura do diálogo. Estamos todos interligados uns aos outros e ao mundo em geral através de uma teia de relacionamentos e quando esta teia se rompe todos são afetados (Zehr, 2012: 47).

Na concepção de Evans e Vaandering (2018: 67) a complexidade que transita em um ambiente escolar é extrema, partindo da compreensão de que cada aluno é diferente. Por isso, nutrir relacionamentos saudáveis é fundamental para ambientes de aprendizagem e de convívio. As experiências refletidas pelas manifestações dos participantes permitem acreditar nos círculos como forma de estabelecer parcerias entre os alunos e criar ambientes propositivos e inclusivos no contexto escolar.

\section{CONSIDERAÇÕES FINAIS}

Acreditamos que as experiências desenvolvidas e seus resultados tenham demonstrado que os Círculos de Construção de Paz corroboram com as práticas voltadas para uma educação dialógica. Exercendo uma influência positiva no que estabelece o fortalecimento de vínculos entre os estudantes, possibilita que os mesmos possam, em um espaço seguro e respeitoso, expressar suas necessidades e angústias. E, a partir dessa vivência, trazer novas possibilidades de coexistência no contexto escolar, familiar e social em que estão inseridos, sentindo-se pertencentes naquele tempo e espaço.

Os participantes manifestaram questões de gênero, de poder fazer uso do diálogo e da confiança entre seus pares como uma possibilidade de socializar seus sentimentos. São sujeitos que carecem de espaços e possibilidades em seus núcleos familiares de expor suas angústias e projetos de vida, de amor, sendo que o círculo vai ao encontro deste momento em que oportuniza a cada participante falar de si.

Portanto, o círculo também acaba exercendo um papel terapêutico, já que essa vivência alivia e distensiona as situações conflituosas internas enfrentadas cotidianamente por estes adolescentes em diferentes espaços, sobretudo sobre seus conflitos pessoais, o que reflete sistematicamente na dinâmica das escolas. Embora não tenhamos, ainda, dados oficiais sobre os índices de violência nas instituições participantes, o que se observa é que houve significativo impacto no ambiente escolar, principalmente na convivência cotidiana, pois aos

Estudios de la Paz y el Conflicto, Revista Latinoamericana, IUDPAS-UNAH, Volumen 1, Número 2, julio-diciembre 2020, pp. 39-54. DOI: $10.5377 /$ rlpc.v1i2.9831. 
poucos vai sendo assumida uma perspectiva inovadora para a solução de conflitos, que ocupa o lugar das tradicionais ações punitivas.

O círculo vem ao encontro da necessidade fundamental do homem que é a convivência em grupo, de sentir-se integrante e ser reconhecido. Também abre a possibilidade ímpar de falar e refletir sobre a fase de vida que vivem em seus diversos contextos. Pensar sobre a qual mundo pertencem e sobre quais são suas perspectivas no presente e projetos de vida futuro enquanto pessoa e estudantes que podem resgatar um tempo perdido, independentemente dos motivos que os levaram a essa condição de frequência nas Turmas de Aceleração de Estudos.

O Círculo de Construção de Paz tem esta capacidade de reconexão entre as pessoas, trazendo o que há de melhor em cada um, num espaço comum. Transcende a simples fala e, por consequência, direciona para um caminho de paz em todos os espaços que o ser humano possa transitar. Paz não significa a inexistência de conflito, paz é a possibilidade de nos fazermos reconhecidos enquanto seres humanos, pertencentes a um espaço e tempo comuns, com pessoas cuidando de pessoas. Paz é estar bem consigo mesmo.

\section{REFERÊNCIAS}

Araújo, A. P., Lorenzoni, N. V. (2015): Práticas restaurativas na escola: relatos e reflexões. Porto Alegre: Armazém Digital.

BNCC - Base Nacional Comum Curricular. Governo Federal. Ministério da Educação-MEC $<$ http://basenacionalcomum.mec.gov.br/images/BNCC_EI_EF_110518_versaofinal site.pdf> (Acesso em 22-03-2020).

Cipave. (2015): Comissão municipal de prevenção de acidentes e violência escolar. Prefeitura Municipal de Caxias do Sul-RS, Secretaria Municipal de Segurança Pública e Proteção Social; Secretaria Municipal da Educação.

Costello, B., Joshua, W. (2011): Círculos restaurativos nas escolas: construindo um sentido de comunidade e melhorando o aprendizado. Intenational Institute For Restorative Practes, Bethleehem. USA.

Evans, K., Vandering, D. (2018): Justiça restaurativa na educação: promover responsabilidade e cura e esperança nas escolas (Trad. Tônia Van Acker). São Paulo: Ed. Palas Athena.

Freire, P. (2002): Educação e atualidade brasileira. São Paulo: Cortez; Instituto Paulo Freire.

Grecco, A., Assumpção, C., Bernardes, C. (2014): Justiça restaurativa em ação: práticas e reflexões. São Paulo: Dash.

Pranis, K. (2010): Processos Circulares. Tradução Tônia Von Acker. São Paulo: Palas Athena.

Lederach, J. P. (2012): Transformação de conflitos, da reflexão a ação. São Paulo: Ed. Palas Athena.

Menda, CC. (2014): “Conflitos na Escola”. Revista mundojovem. Porto Alegre-RS, PUC/RS, 544.

Mullet, J.H., Amstutz, LS. (2012): Disciplina Restaurativa para Escolas. Série da Reflexão a Ação. São Paulo: Ed. Palas Athena.

Pelizzoli, M. (2015): Justiça Restaurativa: caminhos da pacificação social. Caxias do Sul: Ed. da UCS / Recife: Ed. da UFPE.

Estudios de la Paz y el Conflicto, Revista Latinoamericana, IUDPAS-UNAH, Volumen 1, Número 2, julio-diciembre 2020, pp. 39-54. DOI: 10.5377/rlpc.v1i2.9831 
Prefeitura de Caxias do Sul. Caxias da Paz <https://caxias.rs.gov.br/servicos/segurancapublica/diretoria-de-protecao-social/caxias-da-paz> (Acesso em 19-12-2018).

Prefeitura de Caxias do Sul. Cipave. <https://caxias.rs.gov.br/servicos/segurancapublica/cipave $>$ (Acesso em 19-12-2018).

Watson, C., Pranis, K. (2015): Círculos em Movimento: Construindo uma Comunidade Escolar Restaurativa (Trad. Fátima Debastiane). Boston, Massachusetts: Center for Restorative Justice, Suffolk University.

Zehr, H. (2012): Justiça Restaurativa: teoria e prática (Trad. Tônia Van Acher). São Paulo: Ed. Palas Athena.

\section{Legislação e jurisprudência}

Justiça Restaurativa do Brasil. (http://www,amb.cpm.br/jr/docs/cartilha.pdf). Acesso em 2103-2020).

Justiça para $\quad$ o $\quad$ Séc. 21. $<$ http://justica21.web1119.kinghost.net/j21.php?id=80\&pg=0\#.XnZpLOpKjIV>

(Acesso em 21-03-2020).

Lei No 6025. Prefeitura Municipal de Caxias do Sul, Caxias do Sul, Brasil, 12 de junho de 2003.

Lei $N^{o}$ 7754. Prefeitura Municipal de Caxias do Sul, Caxias do Sul, Brasil, 29 de abril de 2014.

Resolução No 225. Conselho Nacional de Justiça, Brasília, Brasil, 31 de maio de 2016.

SMED- Secretaria Municipal da Educação de Caxias do Sul-RS: $<$ https://educacao.caxias.rs.gov.br/> (Acesso em :20-03-2020).

Tribunal de Justiça do RS. (2015): Noções elementares de Justiça Restaurativa- a paz pede a palavra - Escola nacional de Magistratura. Santa Maria - RS.

UNIC/Rio/005. Janeiro $2019 \quad<$ https://nacoesunidas.org/wpcontent/uploads/2018/10/DUDH.pdf> (Acesso em 22-03-2020).

\section{REFERÊNCIA DOS AUTORES}

Sandro de Castro Pitano. Doutor em Educação, é professor do Programa de PósGraduação em Educação (ME/DO) da Universidade de Caxias do Sul (UCS); membro da Action Research Network of the Americas (ARNA) e da Rede Freireana de Pesquisadores, lidera o grupo de pesquisa/CNPq Educação Popular: Ação e Pesquisa.Tem experiência na área de Educação, com ênfase em Filosofia da Educação, Educação Popular e pesquisa participante. scpitano@ucs.br ORCID: 0000-0002-9794-1303

Adilson Martins Corrêa. Mestrado em Inclusão Social e Acessibilidade - Universidade FEEVALE. Doutorando em Educação pela Universidade de Caxias do Sul (UCS), professor da Rede Municipal de Educação de Caxias do Sul - RS (SMED); Formador e Facilitador de Círculos de Construção de Paz: Justiça Restaurativa (JR); Ação/intervenção e Pesquisa.Tem experiência na área de Educação, violência escolar e mediação de conflitos. Email: amcorrea@caxias.rs.gov.br ORCID: 0000-0001-5791-5656 